Pak. j. sci. ind. res. Ser. A: phys. sci. 201255 (2) 98-104

\title{
Preparation of Activated Carbon from Coal by Thermo-Chemical Methods and Its Application on Industrial Effluent for COD Reduction
}

\author{
Farooq Ahmad $^{\text {a* }}$, Abdul Wahid ${ }^{\mathrm{b}}$, Tahira Shafique ${ }^{\mathrm{c}}$ and Amin Ul Haq Khan ${ }^{\mathrm{a}}$ \\ ${ }^{a}$ Sustainable Development Study Centre, GC University, Lahore-54000, Pakistan \\ ${ }^{\mathrm{b}}$ Department of Environmental Science, BZ University, Multan, Pakistan \\ ${ }^{\mathrm{c}}$ Centre for Environmental Protection Studies, PCSIR Laboratories Complex, Lahore-54600, Pakistan
}

(received August 25, 2011; revised November 4, 2011; accepted November 17, 2011)

\begin{abstract}
This study was conducted to assess reduction of chemical oxygen demand (COD) of textile industrial effluent by activated carbons prepared from locally available coal. Activated carbons were prepared by thermal activation at $700{ }^{\circ} \mathrm{C}$ and chemical activation with phosphoric acid $\left(\mathrm{H}_{3} \mathrm{PO}_{4}\right)$ at the same temperature. The complete study was carried out in batch adsorption mode to investigate the effect of operating parameters. The results of COD reduction with thermally activated carbon (TAC) and chemically activated carbon (CAC) compared and optimum operating conditions were determined for maximum reduction. Freundlich adsorption isotherm was applied besides the calculation of optimum treatment parameters for maximum reduction of COD concentration from effluent of the textile industrial plant. The percent yield of TAC and CAC was $69 \%$ and $82 \%$, respectively and maximum percentage reduction of COD concentration under optimum operating conditions using TAC and CAC was $86.9 \%$ and $95.9 \%$, respectively.
\end{abstract}

Keywords: activated carbon, coal, textile wastewater, isotherm, COD

\section{Introduction}

In the last few decades, rapid population and industrialization increase have changed the state of different ecosystems on which human beings depends. Untreated waste water of municipal and industrial area is discharged into rivers and oceans and it affects the quality of water and creates pollution. These wastewater effluents hold huge amount of organic pollutants which effects the ecosystem badly, either in biochemical oxygen demand (BOD), chemical oxygen demand (COD) or total suspended solids (TSS), possibly in the tens of thousands $\mathrm{mg} / \mathrm{L}(\mathrm{Ng}, 2006)$.

In the recent years, the correlation among environmental pollution and industrial action had been mostly recorded (Robinet and Feunteun, 2002). In the industrial sector, the paper and textile industries are of particular importance because they produce considerable amount of wastewater effluents that have a very harmful affect when discharged into the natural environment without treatment. The environmental difficulties related to textile sector are induced chiefly by the large utilization of organic dyes (Peralta-Zamora et al., 2003).

\footnotetext{
*Author for correspondence; E-mail: fagonda182@yahoo.com
}

When the activated carbon is in contact with an aqueous solution, an electric charge is generated. This charge resulted from either the dissociation of the surface functional groups of the carbon or the adsorption of ions from the solution, and depends on the $\mathrm{pH}$ of the solution and on the surface characteristics of the adsorbent (Li et al., 2002). The crystalline structure, surface edges, porosity, variable characteristics of surface chemistry, and high degree of surface reactivity in activated carbon (AC) regulate the adsorption efficiency (Malik et al., 2004). Activated carbon is commonly used as an adsorbent in sugar refining, chemical and pharmaceutical industrial water and wastewater treatment (Ng et al., 2003).

Chemical activation (ChA) is a one-step method used for the preparation of AC. Different chemical activating agents $\left(\mathrm{H}_{3} \mathrm{PO}_{4}, \mathrm{KOH}, \mathrm{H}_{2} \mathrm{SO}_{4}\right.$ etc. $)$ might be used (Macia-Agullo et al., 2004). Major advantages of $\mathrm{ChA}$ are the higher yield, lower temperature of activation (less energy costs), less activation time and, generally, higher development of porosity; among the disadvantages are the activating agents costs and the need to perform an additional washing stage to remove the chemical agent. 
In the present study chemical oxygen demand (COD) parameter for analysis of pre and post treated wastewater was focused. The objectives of the research work were to prepare activated carbon from indigenously available coal for the reduction of COD, investigating various optimum conditions for activated carbon efficiency and application of the prepared activated carbon in treating industrial wastewater and comparison of different application methods.

\section{Materials and Methods}

Sample collection. Wastewater samples from Nishat Textile Industry (located at Hudiara drain, Lahore) were collected by grab sampling technique (Kaul and Gautam, 2002), then these sample aliquots were mixed to form a composite sample and preserved in refrigerator. Samples after collection were analyzed for both physical and chemical parameters (Table 1) but only COD parameter was focused.

Table 1. Laboratory analysis of wastewater samples along with National Environmental Quality Standards of Pakistan (NEQS, 2000)

\begin{tabular}{|c|c|c|}
\hline Parameters & $\begin{array}{l}\text { Wastewater } \\
\text { characterization }\end{array}$ & $\begin{array}{l}\text { NEQS (2000) } \\
(\mathrm{mg} / \mathrm{L})\end{array}$ \\
\hline Colour & Brownish black & --- \\
\hline Odour & Irritating & --- \\
\hline $\mathrm{pH}$ & 5.5 & $6-9$ \\
\hline Temperature $\left({ }^{\circ} \mathrm{C}\right)$ & 31 & $\leq 3{ }^{\circ} \mathrm{C}$ \\
\hline Total solids (mg/L) & 7480 & 3700 \\
\hline Total dissolved solids (mg/L) & 5720 & 3500 \\
\hline Total suspended solids (mg/L) & 1760 & 200 \\
\hline Chemical oxygen demand (mg/L) & 1450 & 150 \\
\hline Sulphide contents $(\mathrm{mg} / \mathrm{L})$ & 8.928 & 1 \\
\hline Chloride contents (mg/L) & 378 & 1000 \\
\hline Total organic carbon $(\%)$ & 0.0279 & --- \\
\hline
\end{tabular}

NEQS = National Environmental Quality Standards.

Activated carbon preparation. Indigenously available coal of Acacia nilotica wood was purchased from wood stall and used for the preparation of activated carbon. The coal obtained from wood stall was not only easily available but was least expensive Activated carbon was synthesized from coal by thermal and chemical activation. For TAC, coal was first washed, dried at 110 ${ }^{\circ} \mathrm{C}$ then burnt in a furnace at $700^{\circ} \mathrm{C}$ for $3 \mathrm{~h}$ to convert it from simple carbon to activated carbon having adsorption sites. For CAC, phosphoric acid was selected because it was an efficient activating agent for synthetic activated carbon with high surface area and pore structure
(Attia et al., 2008). Coal was ground, washed, dried and treated with phosphoric acid at the ratio of $35 \mathrm{~mL} / 250 \mathrm{~g}$ of coal for $24 \mathrm{~h}$ (Gueu et al., 2007). After treatment this carbon was activated in a furnace at $700{ }^{\circ} \mathrm{C}$ for $3 \mathrm{~h}$.

Batch adsorption experiment. To reduce the COD of wastewater by activated carbon, batch adsorption study was carried out at room temperature $25 \pm 3{ }^{\circ} \mathrm{C}$. For experiment $100 \mathrm{~mL}$ of wastewater sample was taken in a $250 \mathrm{~mL}$ conical flask and treated with different weight ( 1 to $10 \mathrm{~g}$ ) of $\mathrm{AC}$ at different $\mathrm{pH}$ (2 to 12) and contact time ( 1 to $5 \mathrm{~h}$ ). Glass beads were used in the conical flask to ensure complete contact between activated carbon and solution.

Chemical oxygen demand (COD) measurement. Measurement of COD was carried out by APHA standard methods (2005) in which $20 \mathrm{~mL}$ of sample was mixed with $0.1 \mathrm{~g}$ of mercuric sulphate and $2 \mathrm{~mL}$ of sulphuric acid reagent followed by addition of $10 \mathrm{~mL}$ potassium dichromate, then it was again mixed with $28 \mathrm{~mL}$ of sulphuric acid reagent. Then, it was placed under condenser and evaporated and condensed for two hours, removed and cooled down added 3 to 4 drops of Ferroin indicator. After complete mixing, it was titrated against ferrous ammonium sulphate; first the colour was faded, then brick red end point appeared. COD of pre and post treated samples were measured and percentage reduction in COD was calculated as follows:

$\%$ Reduction in $\mathrm{COD}=\frac{(\mathrm{X}-\mathrm{Y}) \times 100}{\mathrm{X}}$

$\mathrm{X}=$ the initial COD $(\mathrm{mg} / \mathrm{L})$ of wastewater

$\mathrm{Y}=$ the $\mathrm{COD}(\mathrm{mg} / \mathrm{L})$ of filtrate

Freundlich isotherm. Freundlich equation can be written as:

$$
\mathrm{x} / \mathrm{m}=\mathrm{kCe} \mathrm{e}^{1 / \mathrm{n}}
$$

Where:

$\mathrm{x} / \mathrm{m}=\mathrm{qe}(\mathrm{mg} / \mathrm{g})$ is the amount of COD removed (x) per unit mass of adsorbent $(\mathrm{m}) ; \mathrm{Ce}(\mathrm{mg} / \mathrm{L})$ is the residual COD concentration of aqueous solution; $\mathrm{k}$ and $1 / \mathrm{n}$ are Freundlich constants and measure of adsorption capacity and adsorption intensity, respectively, which can be calculated graphically.

\section{Results and Discussion}

In the present work, activated carbon was prepared by physical (TAC) and chemical (CAC) activation methods. 
Suhas et al. (2007) also reported physical and chemical methods for the preparation of activated carbon.

Activated carbon prepared was observed to be efficient in reduction of COD from industrial wastewater i.e. $87 \%$ and $96 \%$ with TAC and CAC, respectively at treatment time of $4 \mathrm{~h}$. This result matched with Devi and Dahiya (2008) who observed that percentage reduction of COD with mixed adsorbent carbon was $93.84 \%$ after treatment time of $150 \mathrm{~min}$, whereas maximum reduction with commercial activated carbon was $94 \%$ after a treatment time of $180 \mathrm{~min}$.

Yield of activated carbon. The yield of thermally activated carbon was found to be $69 \%$ while that of phosphoric acid activated carbon gave yield of $82 \%$. The rest was lost during washing and activation process (Table 2). This is in accordance with the yield calculated by Alcaniz-Monge and Illan-Gomez (2008) from physical and chemical activation of coal as $68 \%$ and $89 \%$, respectively. One of the important advantages of the chemical process over the physical process was that the yield tends to be greater as carbon burnt to ash was negligible in chemical process.

Table 2. Characteristics of prepared TAC and CAC and their optimum conditions

\begin{tabular}{lll}
\hline \hline Characteristics & TAC & CAC \\
\hline Yield $(\%)$ & 69 & 82 \\
Particle size $(\mathrm{mm})$ & 0.25 & 0.25 \\
Moisture content $(\%)$ & 9.1 & 8.3 \\
Surface area $\left(\mathrm{m}^{2} / \mathrm{g}\right)$ & 710 & 730 \\
Bulk density $\left(\mathrm{kg} / \mathrm{m}^{3}\right)$ & 145 & 157 \\
Porosity $(\%)$ & 83 & 87 \\
Optimum $\mathrm{pH}$ & 2 & 4 \\
Optimum contact time $(\mathrm{h})$ & 4 & 4 \\
Optimum adsorbent dose $(\mathrm{g} / 100 \mathrm{~mL})$ & 8 & 7 \\
Optimum agitation speed $(\mathrm{rpm})$ & 600 & 500
\end{tabular}

$\mathrm{TAC}=$ thermally activated carbon; $\mathrm{CAC}=$ chemically activated carbon.

Mode of study. The study was carried out in Batch adsorption mode. Kadirvelu et al. (2003) has also carried out the similar kind of work in batch adsorption mode. Attia et al. (2008) used both batch adsorption and column adsorption study for the adsorption of dye using activated carbon impregnated with $70 \%$ phosphoric acid and carbonized at $700{ }^{\circ} \mathrm{C}$ reveal the best properties which prevailed upon raising concentration of the treated dye to 150 and $200 \mathrm{mg} / \mathrm{L}$.
Effect of pH on adsorption efficiency. From the results, it was evident that COD reduction was increased from neutral to acidic $\mathrm{pH}$. It was assessed that maximum values were obtained at $\mathrm{pH} 2$ and $\mathrm{pH} 4$ with TAC and CAC, respectively (Fig. 1 and 2) because at low $\mathrm{pH}$ the positively charged species start to dominate and the surface tends to posses positive charge, while the species that are adsorbed were still negatively charged. Due to positively charged adsorbent surface, the increasing electrostatic attraction between positively charged adsorbent particles and negatively charged adsorbate species would lead to boost adsorption of reactive dye (Shukla et al., 2002). Higher adsorption rate of fluoride at low $\mathrm{pH}$ was achieved by Karthikeyan and Illago (2007) in which they showed that the surface charges of the adsorbent play an important role.

Yi et al. (2008) observed that the initial $\mathrm{pH}$ increasing from 3 to 7, the COD reduction efficiency of dye after 60 min of electrolysis increased accordingly. Reddy and Kotaiah (2006) also observed that equilibrium sorption capacity of the activated carbon decreased with the increase in $\mathrm{pH}$ values of reactive dye solution, while increase in adsorption towards basic $\mathrm{pH}$ (8 to12) with TAC and CAC (Fig. 1 and 2) may be due to increase in $\mathrm{OH}^{-}$ions as a result of coagulation of pollutants, and thus, are adsorbed. Malik et al. (2004) observed similar findings, that in alkaline medium, the extent of dye colour removal increase as $\mathrm{pH}$ increased from 8 to 9 .

Effect of contact time. Adsorption increased with increase in contact time because there was much time for pollutants to adsorb on the surface of activated carbon. Initially the percent reduction efficiency of $\mathrm{CAC}$ and commercial activated carbon was almost similar but at $4 \mathrm{~h}$ contact time $\mathrm{CAC}$ had adsorption efficiency $(95.1 \%)$ higher than commercial activated carbon (93\%) but the percent reduction in COD of both these were higher than TAC at pH 2 (Fig. 3). Wang et al. (2008) showed similar observation that the degree of colouration and total organic carbon of the dye solution decreased significantly with an increase in the contact time until equilibrium was attained.

Effect of activated carbon dosage. It was observed that adsorption capacity increased with increased amount of activated carbon due to increased surface area, as more sites were available for adsorption. In case of thermally activated carbon maximum reduction of COD was observed at $8 \mathrm{~g}$ and after that it became constant while in case of chemically activated carbon reduction became maximum at $7 \mathrm{~g}$ (Table 2). 


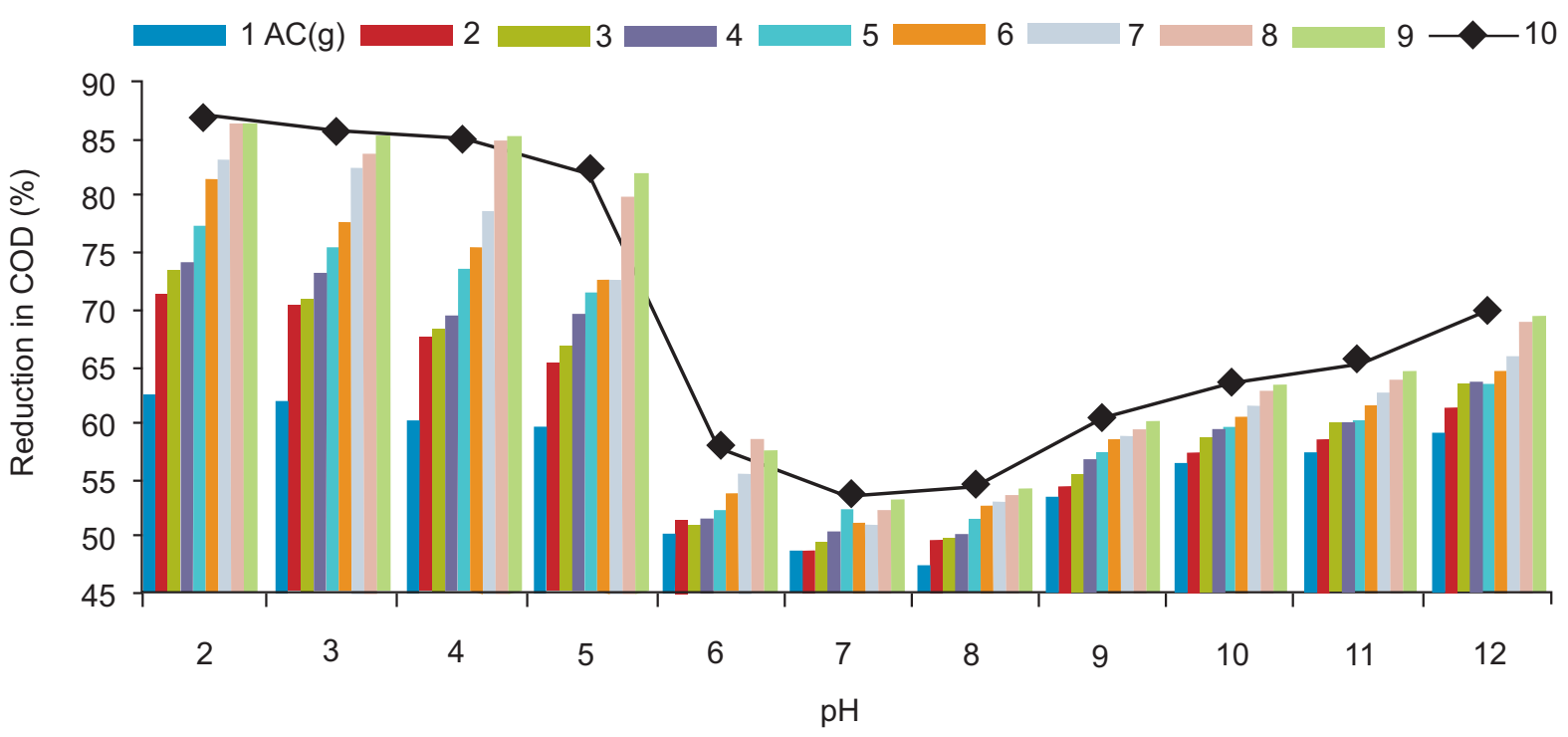

Fig. 1. Effect of $\mathrm{pH}$ and adsorbent dose on percent removal of COD with TAC.

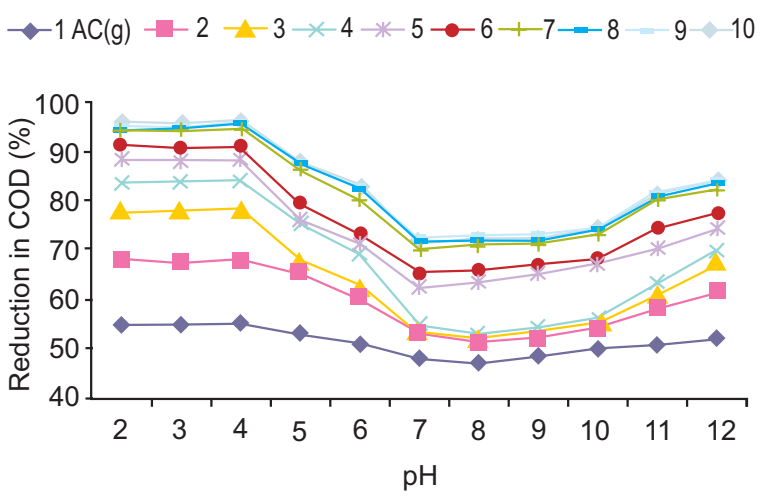

Fig. 2. Effect of $\mathrm{pH}$ and adsorbent dose on percent removal of COD with CAC.

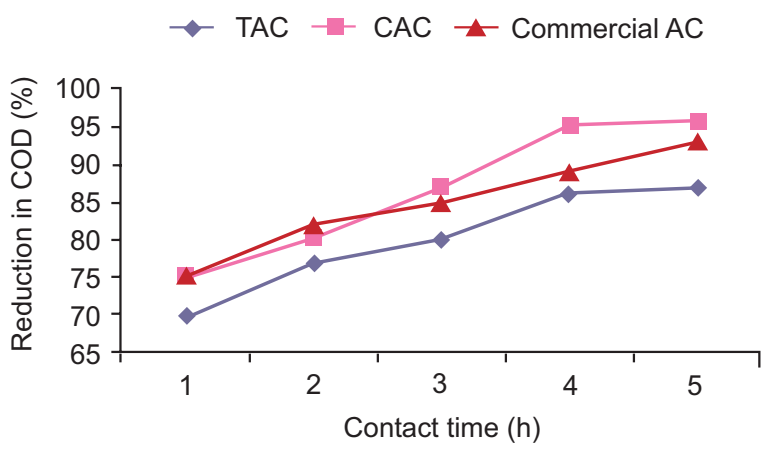

Fig. 3. Effect of contact time on percent removal of COD with TAC, CAC and commercial activated carbon.
It was observed It was also observed that adsorption capacity of CAC was more than that of TAC due to the formation of more adsorption sites by chemically activated carbon (Fig. 4 and 5), that was also observed by Reddy and Kotaiah (2006) that by increasing the dose of commercial activated carbon and sludge derived activated carbon, the percent removal of dye from aqueous solution increased.

Namasivayam and Kavita (2002) were of the view that increase in the adsorption capacity of the adsorbent material with increased dosage indicated the availability of abundance of active sites on its surface. Singh et al. (2008) showed that, initially the percentage removal increases very sharply with the increase in adsorbent dosage (1-5 g/L) but beyond a certain value, the percentage removal reached almost at constant value.

Effect of agitation speed. Agitation speed directly effected the reduction in COD of industrial wastewater. The results showed that adsorption increased with both TAC and CAC by increasing agitation speed and reduction in COD was maximum at 600 and $500 \mathrm{rpm}$, respectively (Table 2). Devi and Dahiya (2008) observed maximum reduction in COD at $600 \mathrm{rpm}$ with mixed adsorbent carbon and commercially available activated carbon. Characteristics of activated carbon are shown in Table 2 which closely resemble with findings of Devi et al. (2008).

Comparison of TAC, CAC and commercial activated carbon. Reduction efficiency of COD with TAC, CAC 
and commercial activated carbon was compared at $\mathrm{pH}$ 2 and 4 as TAC adsorbed efficiently at $\mathrm{pH} 2$ than at $\mathrm{pH}$ 4 while $\mathrm{CAC}$ adsorbed maximum at $\mathrm{pH} 4$. Adsorption of commercial activated carbon was lower than both TAC and CAC at pH 2 but it was higher than TAC at pH 4 (Fig. 4 and 5). Initially at pH 2 the adsorption efficiency of TAC was more than that of CAC but with the increase in carbon dosage this difference became minimized, and at $8-10 \mathrm{~g}$ of activated carbon it became constant with both (TAC \& CAC) adsorbents (Fig. 4). At pH 4 adsorption efficiency of TAC and commercial activated carbon was more than CAC in the start (from 1-2 $\mathrm{g}$ of adsorbent dose) but at adsorbent dose of 3 to $10 \mathrm{~g}, \mathrm{CAC}$ showed more adsorption efficiency than TAC and commercial activated carbon.

Adsorption isotherm studies. Freundlich isotherm is the earliest known relationship describing the sorption equation. This farely satisfactory empirical isotherm can be used for non-ideal sorption that involves

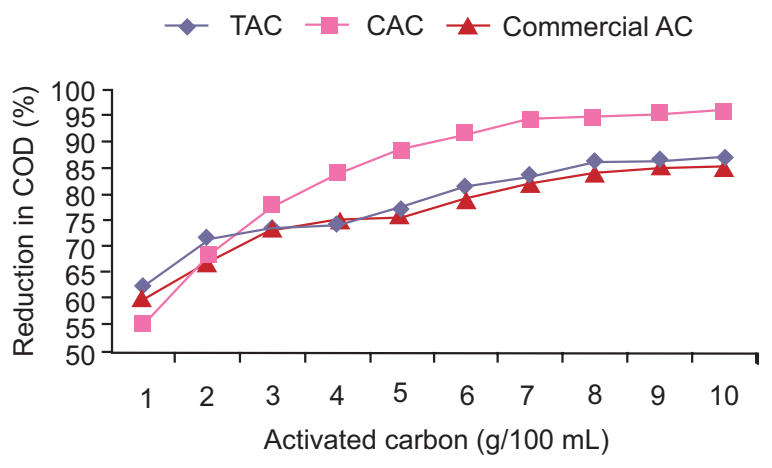

Fig. 4. Comparison of TAC, CAC and commercial $\mathrm{AC}$ at $\mathrm{pH} 2$ and $4 \mathrm{~h}$ contact time.

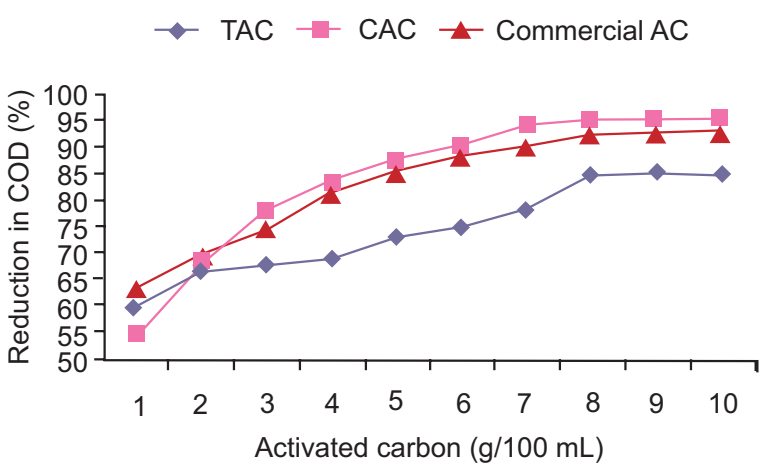

Fig. 5. Comparison of TAC, CAC and commercial $\mathrm{AC}$ at $\mathrm{pH} 4$ and $4 \mathrm{~h}$ contact time. heterogenous surface energy system (Lee et al., 1995). The Freundlich isotherm corresponding to the experimental measurements for TAC and CAC were plotted on log scale as shown in Fig. 6 and 7, respectively. Values of regression coefficient $\left(\mathrm{R}^{2}\right)$ had been calculated from the linear fit and are based on the fit, the respective values of the slope $1 / \mathrm{n}$ and intersect on $\mathrm{y}$-axis taken as $\mathrm{k}$ was also calculated. Values $1 / \mathrm{n}$, $\mathrm{k}$ and regression coefficient $\mathrm{R}^{2}$ for TAC and CAC are shown in Table 3, corresponding to $\mathrm{COD}$ concentration reduction.

As value of $\mathrm{R}^{2}$ was closer to 1 , it showed the fittest of the result of this study in Freundlich isotherm. From the Table 3 it is observed that the data fitted well in Freundlich isotherm with high correlation coefficients $\left(\mathrm{R}^{2}\right)$ value of 0.9587 and 0.9045 for $\mathrm{CAC}$ and TAC, respectively. This high correlation coefficient confirms the applicability of the isotherm. Amuda and Ibrahim (2006) reported that the constants $1 / \mathrm{n}$ and $\mathrm{k}$ were of definite importance in determining

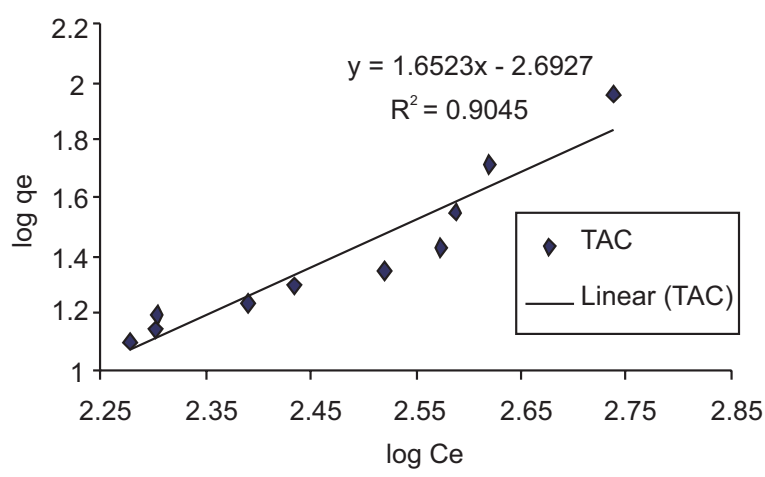

Fig. 6. Freundlich isotherm study of TAC at optimum $\mathrm{pH}$ and contact time.

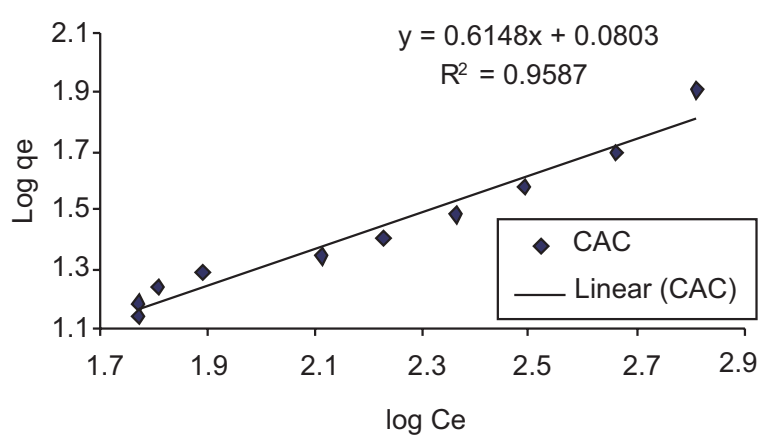

Fig. 7. Freundlich isotherm study of CAC at optimum $\mathrm{pH}$ and contact time. 
the adsorption capacity of organic pollutants from wastewater and reduction of COD concentration by adsorbents. The slope $1 / \mathrm{n}$ was dependent on the order of the change in reduction of COD concentration with the adsorbent dose, while $\mathrm{k}$ was dependent on extent of reduction of COD by the adsorbents. Table 3 shows high value (2.936) of $\mathrm{k}$ indicating good adsorption efficiency of $\mathrm{CAC}$, while higher value of $1 / \mathrm{n}$ indicates more change in effectiveness over different equilibrium concentrations.

Table 3. Freundlich isotherm constants for COD adsorption.

\begin{tabular}{llll}
\hline \hline Activated carbon & $\mathrm{k}$ & $1 / \mathrm{n}$ & $\begin{array}{l}\text { Regression } \\
\text { coefficient }\left(\mathrm{R}^{2}\right)\end{array}$ \\
\hline TAC & 0.0246 & 2.6927 & 0.9045 \\
CAC & 2.936 & 0.0803 & 0.9587 \\
\hline \hline
\end{tabular}

$\mathrm{TAC}=$ thermally activated carbon; $\mathrm{CAC}=$ chemically activated carbon.

\section{Conclusion}

Present study showed that both activated carbons (TAC and $\mathrm{CAC}$ ) are effective for reduction of COD concentration from effluent of textile industry. Adsorption of COD was found to be dependent on $\mathrm{pH}$, treatment time and adsorbent dose. The studied adsorption data fitted well to Freundlich adsorption isotherms. This adsorbent prepared from coal could be a good alternative to expensive activated carbon and hence wastewater treatment process can become very economical. A certain amount of work has already been done on the production of ACs from coal, as well as on the adsorption of inorganic and organic pollutants on coal and coal-derived activated carbons (ACs), there is still a need for more detailed systematic studies.

\section{Acknowledgements}

The authors acknowledge Government College University, Lahore for providing funding for the current study and Director General, Pakistan Council of Scientific and Industrial Research (PCSIR) for providing equipments and laboratories facilities to fulfill this task. The authors are also thankful to Mr. Muhammad Tariq, SO and Mr. Mahtab Ahmad, SSO at PCSIR Labs., Lahore for their sincere guidance during the course of work.

\section{References}

Alcaniz-Monge, J., Illan-Gomez, M.J. 2008. Insight into hydroxides-activated coals: chemical or physical activation. Journal of Colloid and Interface Science, 318: 35-41.

Amuda, O.S., Ibrahim, A.O. 2006. Industrial wastewater treatment using natural material as adsorbent. African Journal of Biotechnology, 5: 1483-1487.

APHA. 2005. Standards Methods for the Examination of Water and Wastewater, $21^{\text {st }}$ edition. American Public Health Association, Washington D.C., USA.

Attia, A.A., Girgis, B.S., Fathy, N.A. 2008. Removal of methylene blue by carbons derived from peach stones by $\mathrm{H}_{3} \mathrm{PO}_{4}$ activation batch and column study. Dyes and Pigments, 76: 282-289.

Devi, R., Dahiya, R.P. 2008. COD and BOD removal from domestic wastewater generated in decentralized sectors. Bioresource Technology, 99: 344-349.

Devi, R., Sigh, V., Kumar, A. 2008. COD and BOD reduction from coffee processing wastewater using avacado peel carbon. Bioresource Technology, 99: 1853-1560.

Gueu, S., Yao, B., Adouby, K., Ado, G. 2007. Kinetics and thermodynamics study of lead adsorption on to activated carbons from coconut and seed hull of the palm tree. International Journal of Environmental Science and Technology, 4: 11-17.

Kadirvelu, K., Kavipriya, M., Karthika, C., Radhika, M., Vennilamani, N., Pattabhi, S. 2003. Utilization of various agricultural wastes for activated carbon preparation and application for the removal of dyes and metal ions from aqueous solutions. Bioresource Technology, 87: 129-132.

Karthikeyan, G., Ilango, S.S. 2007. Fluoride sorption using Moringa indica-based activated carbon. Iranian Journal of Environmental Health Science \& Engineering, 4: 21-28.

Kaul, S.N., Gautam, A., 2002. Water and Wastewater Analysis. pp. 9-10, $1^{\text {st }}$ edition, Daya Publishing House, Delhi, India.

Lee, C.K., Low, K.S., Gan, P.Y. 1995. Removal of some organic dyes by acid treat spent bleaching earth. Environmental Technology, 20: 99-104.

Li, L., Quinlivan, P.A., Knappe, D.R.U. 2002. Effects of activated carbon surface chemistry and pore structure on the adsorption of organic contaminants from aqueous solution. Carbon, 40: 2085-2100.

Macia-Agullo, J.A., Moore, B.C., Cazorla-Amoros, D., Linares-Solano, A. 2004. Activation of coal tar pitch carbon fibres: Physical activation vs. chemical 
activation. Carbon, 42: 1367-1370.

Malik, R., Mukherjee, M., Swami, A., Ranteke, D.S., Sarin, R. 2004. Validation of adsorption efficiency of activated carbon through surface morphology characterization using scanning electron microscopy technique. Carbon Science, 2: 75-80.

Namasivayam, C., Kavita, D. 2002. Removal of Congo Red from water by adsorption onto activated carbon prepared from coir pith, an agricultural solid waste. Dyes and Pigments, 54: 47-58.

NEQS, 2000. The Gazette of Pakistan. Ministry of Environment, Local and Rural Development, Government of Pakistan. S.R.O. 549(1)/2000.

Ng, W.J. 2006. Industrial Wastewater Treatment. pp. 55-64, $1^{\text {st }}$ edition, World Scientific Publishing Company, Nashua, USA.

Ng, C., Marshall, W.E., Rao, R.M., Bansode, R.R., Loss, J.N., Portier, R.J. 2003. Industrial wastewater treatment natural material as adsorbent. $L S U$ Agriculture Centre, Research Extension Bulletin No. 881, Baton Rouge, LA, USA.

Peralta-Zamora, P., Pereira, C.M., Tiburtius, E.R.L., Moraes, S.G., Rosa, M.A., Minussi, R.C., Duran, N. 2003. Decolourization of reactive dyes by immobilized laccase. Applied Catalysis B: Environmental, 42: 131-144.

Reddy, S.S., Kotaiah, B. 2006. Comparative evaluation of commercial and sewage sludge based activated carbons for the removal of textile dyes from aqueous solutions. Iranian Journal of Environmental Health Science \& Engineering, 3: 239-246.

Robinet, T.T., Feunteun, E.E. 2002. Sublethal effects of exposure to chemical compounds: a cause for the decline in Atlantic eels? Ecotoxicology, 11: 265-277.

Shukla, A., Zhang, Y.H., Dubay, P., Margrave, J.L., Shukla, S. 2002. The role of sawdust in the removal of unwanted materials from water. Journal of Hazardous Materials, 95: 137-152.

Singh, C.K., Sahu, J.N., Mahalik, K.K., Mohanty, C.R., Mohanc, B.R., Meikap, B.C. 2008. Studies on the removal of $\mathrm{Pb}(\mathrm{II})$ from wastewater by activated carbon developed from Tamarind wood activated with sulphuric acid. Journal of Hazardous Materials, 153: 221-228.

Suhas, P.J.M., Carrott, M.M.L., Carrott, R. 2007. Lignin from natural adsorbent to activated carbon: A review, Bioresource Technology, 98: 2301-2312. Wang, X., Zhu, N., Yin, B. 2008. Preparation of sludgebased activated carbon and its application in dye wastewater treatment. Journal of Hazardous Materials, 153: 22-27.

Yi, F., Chena, S., Yuan, C. 2008. Effect of activated carbon fibre anode structure and electrolysis conditions on electrochemical degradation of dye wastewater. Journal of Hazardous Materials, 157: 79-87. 